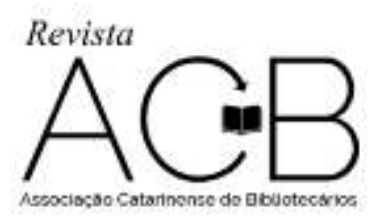

\title{
A BIBLIOTECONOMIA NO SLIDESHARE: INTERATIVIDADE, CAPITAL SOCIAL E ORIENTAÇÕES TEMÁTICAS
}

\author{
Ronaldo Ferreira de Araujo ${ }^{1}$ \\ Jonismar Kendys da Silva Leão ${ }^{2}$ \\ Maria Roselene Cardoso de Barros ${ }^{3}$
}

\begin{abstract}
Resumo: Aborda a representatividade da Biblioteconomia no repositório e site rede social Slideshare por meio de um estudo exploratório de abordagem cibermétrica. O universo é composto de trabalhos resultantes de buscas manuais pelo termo "Biblioteconomia". Os itens são descritos segundo o perfil de seus usuários/autores, níveis de interatividade - por indicadores de capital social - e orientação temática na categorização da rede e classificação taxonômica. Ao todo foram analisados 67 itens publicados entre os anos de 2007 a 2015. Quanto ao perfil dos usuários a maioria era de profissionais bibliotecários e estudantes de Biblioteconomia que juntos representam $65 \%$ do total, com predominância do gênero feminino e interação destinada ao capital social cognitivo. Na orientação temática a categoria "Educação" (42\%) prevalece sobre as demais e na aplicação da taxonomia, é a "Formação e mercado de trabalho do Bibliotecário" (21\%). Os resultados indicam o potencial do Slideshare para disseminação da informação no processo de ensino e aprendizagem, e de atuação profissional na Biblioteconomia.
\end{abstract}

Palavras-chaves: Redes sociais na internet. Slideshare. Biblioteconomia. Disseminação da informação.

\section{INTRODUÇÃO}

Ao longo dos últimos anos percebemos um crescimento demasiado de conteúdos informacionais disseminados na web. O uso intensivo das Tecnologias de Informação e Comunicação (TICs), por meio de equipamentos eletrônicos e interfaces digitais têm contribuído não apenas para o desenvolvimento intelectual, econômico, cultural e político das pessoas, mas também - e de forma ainda mais surpreendente - o social.

É importante destacar o papel da internet como base sólida que cooperou para o surgimento de novas tecnologias e aprimorou diversos serviços para facilitar o cotidiano das pessoas. Assim, a internet tornou-se um meio de comunicação singular e essencial, vez que possibilita ao homem a liberdade para socializar e partilhar informações com outras pessoas de forma instantânea.

Por meio dos recursos da web social o conhecimento produzido é transmitido de maneira rápida, eficiente e em tempo real, sendo possível mensurar seu alcance e interação em ambientes digitais nos seus mais diversos dispositivos informacionais como os blogs e os sites de redes sociais, que são canais voltados à participação e colaboração e que oferecem aos usuários diferentes formas de interagir, aprender e trocar experiências na rede.

Por serem ambientes digitais nos quais os usuários passam cada vez mais tempo conectados, as redes sociais vêm se expandindo e se popularizando. Esse fato tem despertado interesse de várias áreas do conhecimento, em especial da Biblioteconomia e Ciência da Informação, que visualizam nesses ambientes múltiplas possibilidades de estudos sobre os mais diversos dispositivos informacionais e as

\footnotetext{
1 Doutor em Ciência da Informação pelo Programa de Pós-Graduação em Ciência da Informação da Escola de Ciência da Informação da Universidade Federal de Minas Gerais (UFMG).

${ }^{2}$ Graduando em Biblioteconomia pela Universidade Federal de Alagoas (UFAL).

${ }^{3}$ Graduanda em Biblioteconomia pela Universidade Federal de Alagoas (UFAL).
} 


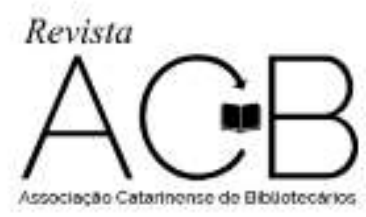

Revista ACB: Biblioteconomia em Santa Catarina, Florianópolis, v. 22, n. 3, p. 483-497, ago./nov., 2017.

ações de informação com vistas a compreensão dos conteúdos e práticas do fenômeno da interação (ARAÚJO, 2014).

Não obstante, a Biblioteconomia, enquanto área tradicional, tem da sociedade uma percepção equivocada e limitada da atuação de seu profissional, e portanto, o desafio de superar os estereótipos negativos carregados de desprestígios que vem sendo vinculados à profissão (WALTER; BAPTISTA, 2007), o que pode ser enfrentado com um movimento de ressignificação da profissão sobretudo no uso prático da internet e dos recursos da web (CORRÊA; ZAMBAN; OLIVEIRA, 2013).

Nesse contexto, estudos que lançam um olhar sobre a presença e representatividade da área em dispositivos informacionais digitais, adquire um importante papel de visibilidade do campo, seja na academia ou na atuação profissional (ARAÚJO; TEIXEIRA, 2013). E com base nesse pressuposto, a presente pesquisa buscou, por meio de um estudo cibermétricos, analisar a representatividade da Biblioteconomia na rede social Slideshare de forma a caracterizá-la quanto ao perfil de seus usuários autores de conteúdo, categorias, níveis de interatividade - por indicadores de capital social - e orientação temática na categorização da rede e classificação taxonômica.

Os estudos métricos da informação na web cooperam, não apenas para organização da informação, como também para avaliar a qualidade e a quantidade do conhecimento humano produzido e disponibilidade na rede. Isso ocorre por meio de compartilhamentos, visualizações, cliques, downloads, comentários, links e entre outros (ARAÚJO, 2015). Ademais, tais estudos são imprescindíveis, pois mostram estatisticamente quais assuntos são mais buscados, discutidos e analisados pelos usuários na web além de contribuir para maior divulgação e visibilidade da pesquisa e dos autores envolvidos, dando-lhes mais credibilidade e reconhecimento.

\section{REDES SOCIAIS NA INTERNET, AÇÕES DE INFORMAÇÃO E CAPITAL SOCIAL}

Em linhas gerais as redes sociais são estruturas abstratas e podem ser entendidas como um conjunto de participantes autônomos, unindo ideias e recursos em torno de valores e interesses compartilhados. Os mesmos sujeitos, autônomos, "quando dotados de recursos e capacidade, organizam as suas ações nos seus próprios espaços políticos, havendo uma valorização dos elos informais e das relações existentes, em decorrência das estruturas hierárquicas” (MARTELETO, 2001, p.72).

Para Tomaél, Alcará e Chiara (2005, p. 93) os indivíduos estão inseridos na sociedade por meio das relações que desenvolvem durante toda sua vida e "as relações que as pessoas desenvolvem e mantêm é que fortalecem a esfera social" sendo a própria natureza humana que "nos liga a outras pessoas e estrutura a sociedade em rede".

Assim, a rede pode ser entendida como "um conjunto de objetos, ou nós, e um mapeamento ou descrição do relacionamento entre os objetos. No caso de redes sociais, os objetos referem-se às pessoas ou grupos de pessoas" (ALDRICH; ZIMMER, 1986). O que nos faz compreender que as pessoas, mesmo involuntariamente, são atraídas para algum tipo de rede ou agenciamento como consequência de seu convívio natural.

Os avanços tecnológicos contribuíram para que a sociedade passasse por transformações que repercutiram diretamente na vida das pessoas. As ações de informação, a começar pelo seu acesso, por exemplo, tornou-se mais rápido e fácil, de modo a diminuir a distância entre o usuário e a fonte de informação. O advento da internet e sua popularização na década de 1990 foi fator base para a explosão das Tecnologias de Informação e Comunicação (TIC's), servindo como o alicerce para a difusão da interconexão das redes (CASTELLS, 2003).

Por ser considerada uma ferramenta/meio que possibilita maior interatividade na troca de informação, a internet, a partir de sua evolução, vem cooperando para o desenvolvimento de diversos campos de pesquisa e ampliando suas potencialidades. Uma das principais vantagens de sua utilização, 


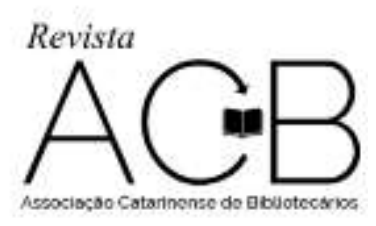

Revista ACB: Biblioteconomia em Santa Catarina, Florianópolis, v. 22, n. 3, p. 483-497, ago./nov., 2017.

em favor da sociedade, é a conectividade entre pessoas e a possibilidade de compartilharem informações em rede virtual.

As redes sociais na internet, por sua vez, surgem como uma alternativa de interação para que pessoas, geograficamente distantes, possam continuar trocando informações e, consequentemente, alimentando seu convívio social. O que se percebe é que tais redes "ampliaram as possibilidades de conexões, ampliaram também a capacidade de difusão de informações que esses grupos tinham" uma vez que "essas informações são muito mais amplificadas, reverberadas, discutidas e repassadas", dando assim "mais voz às pessoas, mais construção de valores e maior potencial de espalhar informações" (RECUERO, 2009, p. 25).

O desenvolvimento e evolução da internet para uma web mais dinâmica e responsiva enriqueceu as trocas informacionais e a comunicação mediada por computador. A web 2.0 ou web social, é definitivamente um ambiente colaborativo cuja interatividade e a centralidade no usuário predomina, visto que este ambiente é formado, construído e constantemente atualizado pelos próprios usuários. É considerada uma nova concepção pois, diferente de sua antecessora, é descentralizada e confere aos usuários uma papel mais ativo e participante sobre a criação, seleção e troca de conteúdos em ambientes e plataformas abertas (BLATTMANN; SILVA, 2007, p. 198). Para Primo (2007, p. 1), "a web 2.0 caracteriza-se por potencializar as formas de publicação, compartilhamento e organização de informações, além de ampliar os espaços para a interação entre os participantes do processo". Com isso, o usuário além de consumir informação, passa a produzi-la à medida que novos mecanismos potencializam a interação e colaboração.

Essa interação mediada a partir dos sites de redes sociais tem sido denominada de capital social e refere-se a um valor constituído entre os atores sociais. O capital social de uma rede pode ser relacional ou cognitivo ou a combinação de ambos.

$\mathrm{O}$ capital relacional está ligado às informações rapidamente difundidas por puro apelo relacional com a finalidade de estreitar e manter os laços sociais na rede. O objetivo é, justamente, ampliar a intimidade entre os atores na rede, através da publicação recíproca de informações de caráter mais pessoal. (RECUERO, 2009). O capital social cognitivo, por sua vez, aponta para as informações disseminadas que possuem um apelo informacional maior. Seu objetivo não é aprofundar laços sociais, mas, especificamente, informar ou gerar conhecimento. (RECUERO, 2009).

Para Recuero (2009) o capital social é uma construção que tem ligação direta com a forma de como o autor se comporta em rede gerando, assim, consequências positivas ou negativas que são verificadas por seus valores, a saber, a visibilidade, a reputação, a popularidade e a autoridade. A autora esclarece que os valores percebidos no capital social são relacionados aos sites de redes sociais e sua apropriação pelos autores e apresenta os tipos de capital social mais encontrados. A primeira delas, a visibilidade é "constituída enquanto um valor porque proporciona que os nós sejam mais visíveis na rede [...] e quanto mais conectados os nós de uma rede, maiores as chances de que ele receba determinado tipo de informação que estão circulando nesta rede" (RECUERO, 2009, p. 108).

A reputação é "compreendida como a percepção construída de alguém pelos demais atores e, portanto, implica três elementos: o "eu" e o "outro" e a relação entre ambos. Está relacionada ao nosso comportamento e como ajudamos outras pessoas a formarem suas impressões sobre nós" (RECUERO, 2009, p. 109).

A autora destaca ainda que a popularidade, por sua vez, refere-se ao valor relativo à posição de um ator dentro de sua rede social. "Um nó mais centralizado na rede é mais popular, porque há mais pessoas conectadas a ele e, por conseguinte, esse nó poderá ter uma capacidade de influência mais forte que outros nós na mesma rede. Também está relacionada ao número de comentários" (RECUERO, 2009, p. 111). O valor social autoridade "é uma medida de influência, da qual se depreende a reputação. É o poder de influência de um nó na rede social” (RECUERO, 2009, p. 113). Sendo assim, a autoridade é 


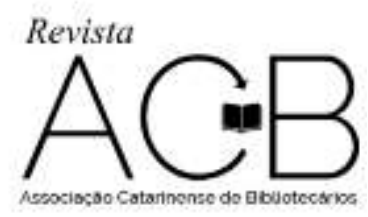

Revista ACB: Biblioteconomia em Santa Catarina, Florianópolis, v. 22, n. 3, p. 483-497, ago./nov., 2017.

decorrente não apenas do capital social relacional, mas, igualmente, do capital social cognitivo (RECUERO, 2009).

Por fim, para as redes sociais esses indicadores do capital social são importantes instrumentos de análise de uma rede e seus relacionamentos. Hoje, torna-se notável o papel que as redes sociais desempenham no processo de disseminação da informação, visto que a cada dia mais as pessoas e/ou instituições a utilizam para seu benefício.

\section{O SLIDESHARE: UM AMBIENTE ACADÊMICO E PROFISSIONAL}

O Slideshare não foi desenvolvido exclusivamente com a proposta de ser uma rede social na internet, no entanto, a forte interação entre os indivíduos que fazem a utilização desta plataforma a transformou em um ambiente propício a transferência de informação e ao estabelecimento de laços sociais entre seus usuários.

Criado em 2006, essa rede foi adquirida pelo LinkedIn, em 2012, e desde então tem tido um crescente aumento de conteúdos profissionais, com apresentações, infográficos, documentos e vídeos, itens que uma vez compartilhados, possibilitam ao usuário estabelecer sua reputação e criar mais oportunidades profissionais (SLIDESHARE, 2016). Trata-se de:

[...] um serviço Web destinado à partilha pública de transparências de apresentações. Recentemente, começou a aceitar outros tipos de documentos, mas o seu êxito e a razão fundamental da sua procura continuam a ser o acesso a transparências. Permite criar redes sociais entre autores e promover diálogos inspirados por essas apresentações. Várias das transparências tornadas públicas têm valor pedagógico elevado. Alguns professores, sobretudo do ensino superior, também colocam lá módulos dos seus cursos mais populares (FIGUEIREDO, 2012, p. 87-88).

A adesão por estudantes, professores e profissionais das mais diversas áreas tem promovido um aumento significativo do uso do SlideShare que tem registrado mais de 70 milhões de visitantes únicos mensais, com cerca de 13.000 novas apresentações adicionados diariamente (GUEDES, 2016), tendo atingido inclusive, em janeiro de 2016, a marca de 18 milhões de uploads (THELWALL; KOUSHA, 2016).

A plataforma pode ser considerada um repositório de trabalhos científicos e não acadêmicos, pois diversos pesquisadores e profissionais o utilizam para disseminar e/ou divulgar suas produções e apresentações de seu contexto de atuação. Desta forma, o espaço pode contribuir como uma alternativa na busca por referência à construção de novas pesquisas e práticas (SLIDESHARE, 2016).

Vale ressaltar que nem sempre os trabalhos depositados no site são efetuados pelos próprios autores, mas por vezes são upados por outras pessoas que se interessaram pela temática e resolveram divulgá-la. Recentemente, foi incorporado uma aba com indicadores estatísticos de um item no Slideshare (ex. Figura 1) que permite verificar o quanto o trabalho repercute na rede e mobiliza interações em torno de si. 


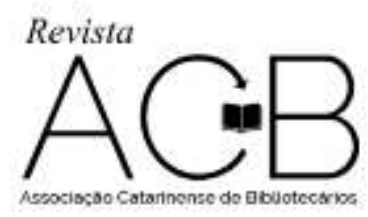

Revista ACB: Biblioteconomia em Santa Catarina, Florianópolis, v. 22, n. 3, p. 483-497, ago./nov., 2017.

FIGURA 1 - Campo de estatística de uma publicação

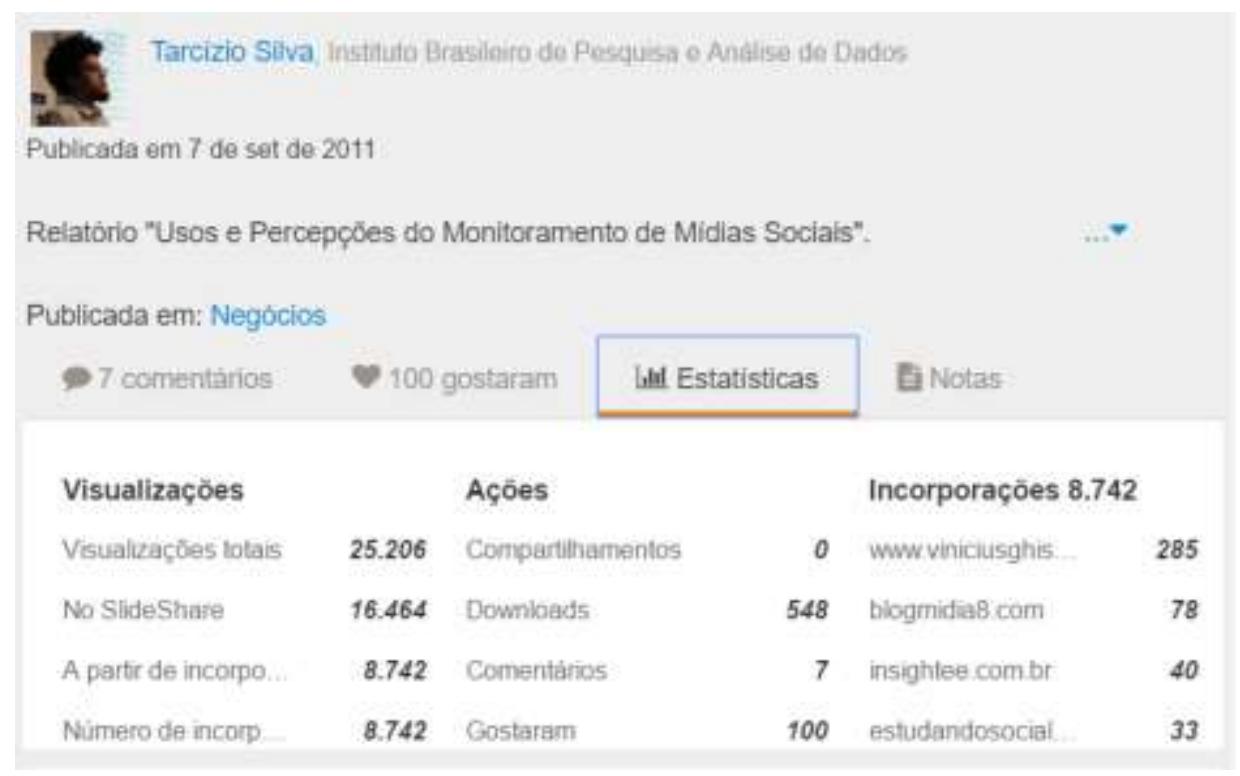

Fonte: www.pt.slideshare.com

A Figura exemplifica essa funcionalidade e representa as estatísticas de desempenho de uma publicação com dados sobre sua visibilidade e audiência alcançada (por meio das visualizações), das ações de informação de disseminação e interação (nos compartilhamentos, comentários e avaliações) bem como de acesso e uso (nos downloads e incorporações).

No contexto educacional esses dados denotam a real participação ou a utilização dos itens como fontes de informação, uma vez que alguns usuários fazem uso do Slideshare, também, como repositório para armazenar e compartilhar conteúdos discutidos em sala de aula. Isso colabora para fortalecer laços sociais entre indivíduos de mesmo grupo, auxilia no processo de troca de conhecimentos, facilita a abertura de discussões, entre outros.

Esses aprimoramentos da rede e o aumento do seu número de usuários, bem como a diversidade de conteúdo nela disponibilizado têm feito alguns autores como Thelwall e Kousha (2016) concluírem que o SlideShare vem se ressignificando e se tornou um repositório de um grande número de apresentações acadêmicas, profissionais e de outros tipos. Para os autores, pela própria web e outros sites, como a Wikipedia, pode, por exemplo, fornecerem informações e conhecimentos especializados que anteriormente eram difíceis de se encontrar ou permaneciam inéditos (não publicados), o SlideShare pode ser particularmente útil no ensino e formação.

\section{MATERIAL E MÉTODO}

Trata-se de uma pesquisa de caráter exploratório desenvolvida a partir da investigação do conteúdo biblioteconômico encontrado no site de rede social Slideshare. O estudo se deu por meio do levantamento quantitativo de temáticas encontradas, dos autores que as produzem e as disseminam nesse ambiente e dos mecanismos utilizados para a interação. Uma pesquisa exploratória é aquela que busca reunir dados, informações, padrões, ideias, hipóteses sobre um problema ou pesquisa com pouco ou nenhum estudo anterior (MUELLER, 2007) tendo a finalidade de "melhor adequar o instrumento de medida à realidade que se pretende conhecer", bem como compreender "a variável de estudo tal como se 


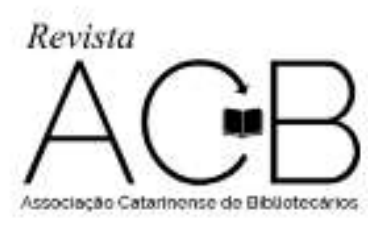

Revista ACB: Biblioteconomia em Santa Catarina, Florianópolis, v. 22, n. 3, p. 483-497, ago./nov., 2017.

apresenta, seu significado e o contexto onde ela se insere. Pressupõe-se que o comportamento humano é melhor compreendido no contexto social onde ocorre" (PIOVESAN; TEMPORINI, 1995, p. 321).

A pesquisa foi realizada entre o mês de novembro de 2015, período de coleta dos dados, e maio de 2016, para descrição e análise. No campo de busca do Slideshare <https://www.slideshare.net/search $>$ foi realizada uma consulta pelo termo "Biblioteconomia", a qual indicou um elevado número de páginas com resultados, cerca de duzentas. Para estabelecer um recorte, como critérios de busca, foram escolhidos apenas os trabalhos em língua portuguesa que tratassem de assuntos relacionados à Biblioteconomia.

A princípio, pretendia-se investigar uma amostra intencional das 100 primeiras publicações que atendessem aos requisitos citados. Porém, além de algumas duplicidades, vários resultados foram descartados por não se enquadrarem dentro da temática solicitada, sendo que a partir da sexta página, percebeu-se que os documentos postados não possuíam atinência temática alguma com a área de Biblioteconomia, ficando para a análise empírica 67 trabalhos.

A abordagem cibermétrica foi a escolhida para análise dos dados por ser considerada de maior abrangência e mais adequada para estudos quantitativos dos dispositivos de informação em ambientes digitais com a finalidade de mensurar "os produtos (blogs, listas ou fóruns de discussão, comunidades virtuais, temas, assuntos, entre outros) e atores (blogueiros, membros, usuários, instituições, moderados, tutores, entre outros) sociais, com o propósito de medir os aspectos comunicativos das articulações que eles estabelecem na web" (ARAÚJO, 2015, p.52).

Os trabalhos são descritos segundo o perfil de seus usuários/autores; distribuição temporal; os níveis de interatividade - por indicadores de capital social (RECUERO, 2009) - as categorias dispostas no Slideshare, nas quais os próprios usuários indexaram seus itens; e a orientação temática na categorização da rede e classificação taxonômica em 10 categorias de assunto da área da Biblioteconomia e Ciência da Informação (ODDONE; GOMES, 2003).

Segundo Recuero (2009, p. 107), "um dos elementos mais relevantes para o estudo da apropriação dos sites de redes sociais é a verificação dos valores construídos nesses ambientes". Para os indicadores de visibilidade, consideramos as visualizações e compartilhamentos, já para os indicadores de autoridade e reputação, consideramos o perfil dos autores; e, por fim, para os indicadores de popularidade, levamos em consideração as curtidas, comentários e downloads.

\section{ANÁLISE E DISCUSSÃO DOS DADOS}

Os autores, pessoas responsáveis por publicar seus trabalhos no Slideshare, formam um grupo específico de indivíduos cujo objetivo é a difusão de todo o conhecimento produzido, num sistema mútuo de compartilhamento de conteúdos. Diante de sua importância e seu papel, analisamos a formação profissional desses autores, que estão diretamente envolvidos na rede social.

De acordo com Araújo (2014) compreender “quem são os atores e como se articulam pode contribuir na melhor caracterização de suas ações, bem como dos dispositivos que dispões e dos artefatos que os condicionam". A partir da análise do perfil dos que publicam conteúdos sobre Biblioteconomia no Slideshare, identificamos um total de 52 perfis, que geraram as 67 publicações. Essa diferença ocorreu, pois alguns perfis apresentaram mais de uma publicação - o que fez com que o número destas fosse maior que a de perfis de usuários.

Assim, encontramos 18 perfis de Bibliotecários, 16 de graduandos em Biblioteconomia, 02 de professores que atuam na área de Biblioteconomia e Ciência da Informação, 01 perfil institucional de Biblioteca, 01 de Graduando em Jornalismo, 01 perfil de jornalista, 01 perfil institucional de Núcleo de Tecnologia da informação, 01 perfil de professor de história e por fim 11 perfis não divulgaram quaisquer informações que ajudassem a identificar a atuação profissional do autor. Juntos, os profissionais bibliotecários e estudantes da área representam $65 \%$ do total de perfis analisados. Constatou-se também 


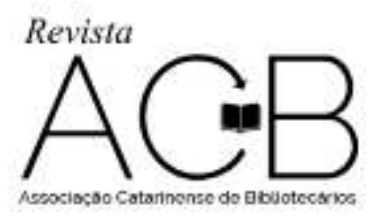

Revista ACB: Biblioteconomia em Santa Catarina, Florianópolis, v. 22, n. 3, p. 483-497, ago./nov., 2017.

que, dentre os 52 perfis investigados, 20 são do gênero feminino e 17 do masculino. Outros 15 não foi especificado ou não se aplica, como perfis coletivos ou instituições. Os trabalhos analisados foram publicados entre os anos de 2007 e 2015 e sua distribuição por ano pode ser observada no Gráfico 1.

GRÁFICO 1: Distribuição de publicações de trabalhos por ano

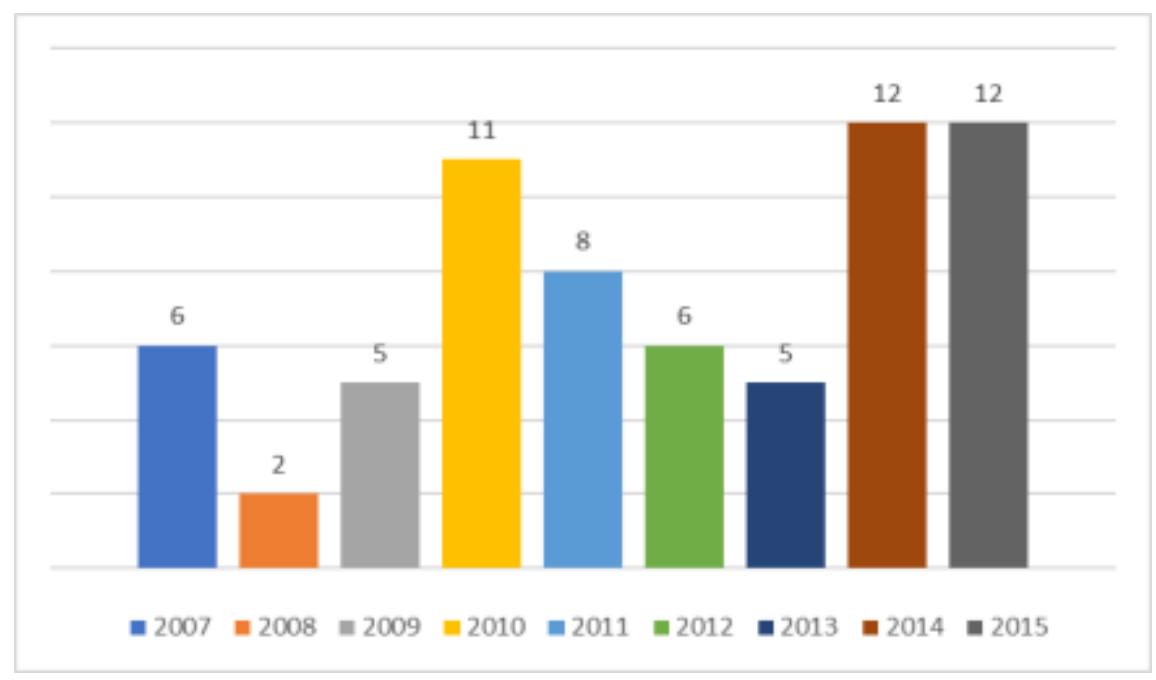

Fonte: Elaborado pelos autores, dados da pesquisa (2016)

Ao longo dos anos, ocorreu uma variação no crescimento do conteúdo relacionado a Biblioteconomia publicado na rede social Slideshare. O início é flutuante, pois o ano de 2007, por exemplo, apresentou seis trabalhos relacionados a área, esse número cai para dois em 2008, sobe para cinco em 2009 com crescimento para $11 \mathrm{em} \mathrm{2010.} \mathrm{No} \mathrm{entanto,} \mathrm{a} \mathrm{partir} \mathrm{de} 2010$ o movimento é decrescente voltando para cinco em 2013. Em 2014 e 2015, constatou-se um melhor índice entre todos os anos listados, ambos com 12 trabalhos publicados.

Ressalta-se que, para esta coleta, não houve prejuízo significativo atribuído ao ano de 2015, uma vez que a mesma abrangeu aproximadamente 11 meses. É importante destacar que os trabalhos disseminados neste site são oriundos de diversas regiões no Brasil. A Região Sudeste apresentou 36\% das publicações, seguido da região Nordeste, com $24 \%$. A região Sul do país obteve $13 \%$ das publicações e a Centro-Oeste, 9\%. Já a região Norte apresentou apenas 3\% de trabalhos publicados. Por fim, verificou-se que $15 \%$ dos trabalhos não apresentaram os locais de suas apresentações. A esses, atribuímos a categoria de "Não Divulgado".

Diante dessa análise, percebemos que a maior concentração de publicações é procedente das regiões Sudeste e Nordeste, o que se conforma com os dados de formação da área no país que possui oferta de graduação com mais de 40 cursos concentrados na região Sudeste, tendo em segundo lugar a região Nordeste e em terceiro a região Sul do país (ARAÚJO; TEIXEIRA, 2013). Dada a vocação para o cunho educacional do SlideShare considera-se haver uma coerência quanto as proporções de trabalhos por região, uma vez que as regiões com maiores ofertas na formação acadêmica são aquelas mais producentes.

De acordo com o conteúdo publicado no Slideshare foi identificado também que os usuários utilizam uma média de 26 páginas por documentos disponibilizados, sendo raro apresentações muito extensas. Quanto aos valores construídos no ambiente o primeiro analisado foi o de visibilidade percebido no alcance das publicações por meio das visualizações obtidas.

A soma das visualizações dos 67 documentos sobre Biblioteconomia totaliza 133.770 acessos dando uma média de 2 mil visualizações por item. Esse número representa o indicador de visibilidade 


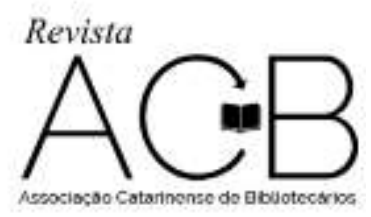

Revista ACB: Biblioteconomia em Santa Catarina, Florianópolis, v. 22, n. 3, p. 483-497, ago./nov., 2017.

obtido pelas publicações e refere-se à audiência as mesmas atingem (RECUERO, 2009) e indicam uma comunidade de atenção em torno do que é publicado sobre Biblioteconomia na rede. O Quadro 2 apresenta as 10 publicações que obtiveram o melhor desempenho no quesito visibilidade.

QUADRO 2. Publicações sobre Biblioteconomia mais visualizadas no Slideshare

\begin{tabular}{|c|l|c|}
\hline Posição & \multicolumn{1}{|c|}{ Título da Apresentação } & Visualizações \\
\hline $\mathbf{1}^{\mathbf{o}}$ & Introdução a Biblioteconomia para bibliotecas escolares & 12.383 \\
\hline $\mathbf{2}^{\mathbf{o}}$ & Automação de Bibliotecas: Gnuteca & 8.554 \\
\hline $\mathbf{3}^{\mathbf{o}}$ & Automação de Bibliotecas & 8.445 \\
\hline $\mathbf{4}^{\mathbf{0}}$ & $\begin{array}{l}\text { Fontes de informação para concursos em biblioteconomia: a experiência } \\
\text { do Blog Biblioteconomia para Concursos }\end{array}$ & 8.158 \\
\hline $\mathbf{5}^{\mathbf{0}}$ & $\begin{array}{l}\text { Produção do registro do conhecimento I: Conceito, evolução e aspectos } \\
\text { das bibliotecas }\end{array}$ & 7.365 \\
\hline $\mathbf{6}^{\mathbf{0}}$ & Perspectivas da web semântica para a biblioteconomia & 7.069 \\
\hline $\mathbf{7}^{\mathbf{o}}$ & Guy Kawasaki aplicado ao Blog Biblioteconomia para Concursos & 7.033 \\
\hline $\mathbf{8}^{\mathbf{o}}$ & Movimento estudantil: o enfoque da Biblioteconomia & 5.930 \\
\hline $\mathbf{9}^{\mathbf{o}}$ & $\begin{array}{l}\text { Ciência da Informação e Biblioteconomia, novos conteúdos e espaços de } \\
\text { atuação }\end{array}$ & 5.840 \\
\hline $\mathbf{1 0}^{\mathbf{o}}$ & Como ficar rico com Biblioteconomia & 5.092 \\
\hline
\end{tabular}

Fonte: Elaborado pelos autores, dados da pesquisa (2016)

A publicação que obteve maior audiência é sobre 'Introdução a Biblioteconomia para bibliotecas escolares' com 12.383 visualizações, seguida de 'Automação de Bibliotecas: Gnuteca' com 8.554 e outra sobre 'Automação de Bibliotecas' com 8.445. A quarta aborda 'Fontes de informação para concursos em biblioteconomia: a experiência do Blog Biblioteconomia para Concursos' com 8.158 visualizações.

Para além das visualizações as interações indicam o quanto, após acessados, os documentos mobilizam os usuários às práticas e ações de informação expressas nos recursos de avaliações (curtidas), disseminação (compartilhamentos) e opiniões (comentários). As curtidas apresentam uma ideia favorável ao autor, legitimando a sua positividade em apoio ou concordância. O compartilhamento representa a disseminação da informação, ou seja, o usuário reproduz o mesmo conteúdo através do seu perfil e toma para si a função de enunciador. Já o comentário pode apresentar questionamento e discordância acerca da informação postada. (RECUERO; SOARES, 2013).

A ação de curtir um item no SlideShare desempenha um papel significativo no que tange a satisfação do usuário, e não apenas sinaliza o acesso seguido de aprovação como pode servir de estimule para que outros usuários gostem também. Dos documentos analisados $57 \%$ foram sinalizados com uma ou mais curtidas. A mais assinalada se referia à temática "Arquitetura da informação e design", com 28 curtidas, sendo também a mais compartilhada pelos usuários apresentando 38 compartilhamentos. O compartilhamento exige um pouco mais do usuário do que penas curtir é uma sinalização de concordância e distribuição desse conteúdo para sua rede de seguidores, e teve um desempenho menor, uma vez que apenas $23 \%$ dos documentos analisados foram compartilhados ao menos uma vez.

A última ação de interação analisada é a de 'comentário' que permite ao usuário da rede se expressar e emitir elogios, críticas e opiniões ou mesmo tirar dúvidas sobre determinado conteúdo. Os comentários atuam como indicador de engajamento entre os usuários e pode, por exemplo, contribuir na análise e medição da popularidade (RECUERO, 2009). Esse indicador é menor ainda que o de compartilhamento, apenas $15 \%$ das publicações foram comentadas.

Até esse ponto podemos observar que quando comparados os valores das ações de visualizar curtir - compartilhar - comentar há uma diminuição significativa do primeiro ao último, ou seja, muito 


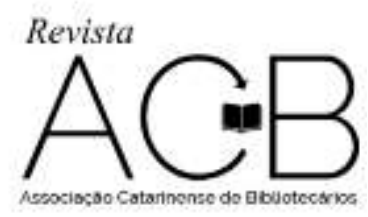

Revista ACB: Biblioteconomia em Santa Catarina, Florianópolis, v. 22, n. 3, p. 483-497, ago./nov., 2017.

visualizam, alguns curtem, poucos compartilham e um número menor ainda comenta. De acordo com Araújo (2014) esse comportamento está em consonância com estudos de interação em ambientes digitais que tem se reproduzido o cenário no qual se confirma que a boa maioria dos usuários mais observa do que participa.

Ressalte-se ainda que a publicação que obteve mais comentários abordava o assunto sobre "Fontes de Informação para Concursos em Biblioteconomia de autoria" de Gustavo Henn, com 44 comentários. É nos comentários que a conversação em rede acontece sendo a interação que mais oferece elementos para uma análise mais qualitativa dos diálogos que são estabelecidos entre os usuários. A Figura 2 exemplifica isso com comentários e resposta em torna da publicação sobre "Automação de Bibliotecas: Gnuteca". Um usuário pergunta sobre uma função de importação de dados, ao passo que o perfil responsável pelo conteúdo responde indicando contato do fabricante. Por fim um outro usuário entra na conversação e elogia o material expressando que ele será útil para implantação na instituição onde trabalha.

FIGURA 2. Conversação entre os usuários do Slideshare

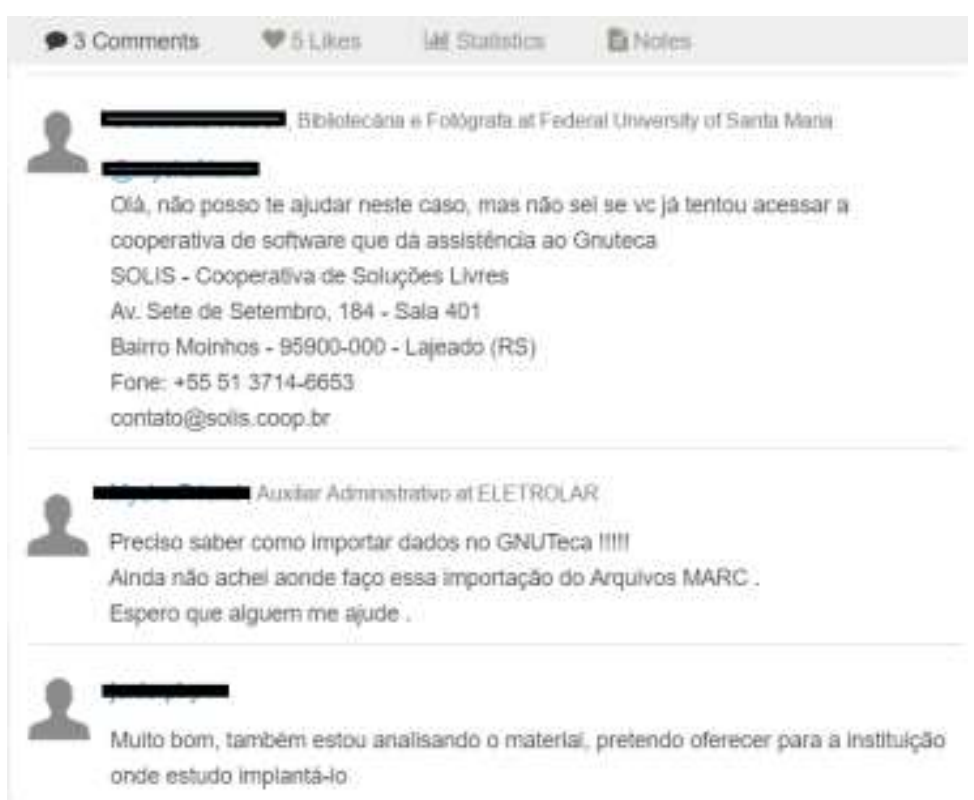

Fonte: www.pt.slideshare.net

Além dessas ferramentas disponibilizadas nessa rede para fins de interação, o usuário também pode fazer o download da publicação, editá-la e/ou utilizá-la para referência ou propósitos similares. O download é um indicativo de acesso para posterior uso. Observa-se ainda que a maioria das publicações, isto é, 91\% delas, apresentaram pelo menos um download deixando um número bem baixo de documentos que nunca foram baixados. A publicação "Glossário de Biblioteconomia e Documentação" que tem como propósito a definição dos termos técnicos da área de Biblioteconomia obteve o maior número de downloads, foram 176 downloads.

O Slideshare dispõe de 40 categorias nas quais o usuário ao fazer upload de uma publicação pode enquadrar para aferir uma aproximação temática ou de assunto principal. Esse processo contribui para a classificação e recuperação da informação, facilitando no momento das buscas. O Gráfico 2 apresenta a distribuição dos documentos pelas categorias informadas pelos os usuários e com. 


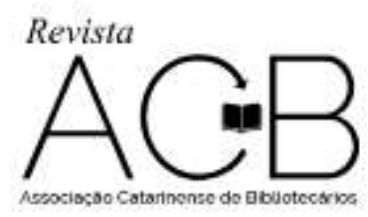

Revista ACB: Biblioteconomia em Santa Catarina, Florianópolis, v. 22, n. 3, p. 483-497, ago./nov., 2017.

GRÁFICO 2: Publicações por categorias do Slideshare

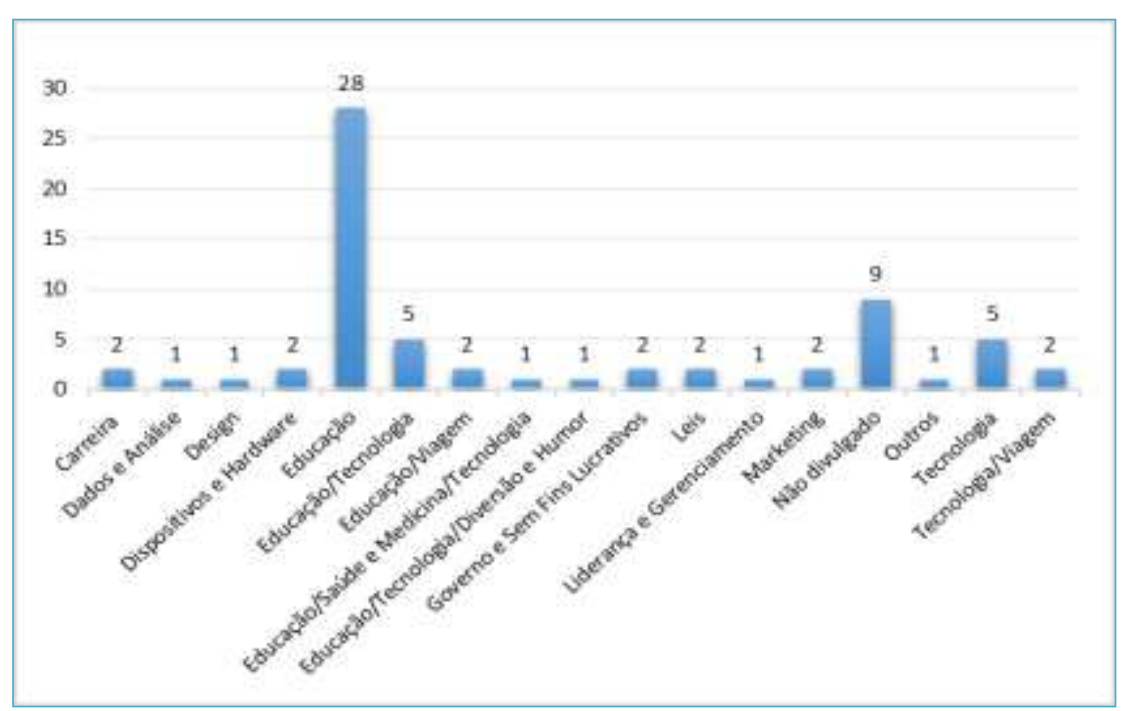

Fonte: Elaborado pelos autores, dados da pesquisa (2015).

Pode-se observar que a categoria mais utilizada pelos usuários para submeter suas publicações foi "Educação", com 28 itens, que se somados a "Educação/Tecnologia" com cinco, totalizam 33 documentos, ou seja, representa $49 \%$ do total analisado. Esse resultado, por exemplo, reflete a utilização do Slideshare como instrumento de auxílio ao ensino, visto que algumas publicações apresentam conteúdos de temas estudados em sala de aula. Isso se deve, principalmente, ao compartilhamento e divulgação de variados conteúdos informacionais que cooperam, não só para o processo de aprendizagem do aluno, mas também para sua formação profissional. Uma das grandes benesses que esse tipo de rede social tem proporcionado é um ambiente educacional mais interativo, pois permite o estreitamento e fortalecimento da comunicação entre os atores envolvidos (professores e alunos). O Slideshare não permite a inclusão de um item e mais de uma categoria, mas também não obriga que para ser feito o upload o usuário informe a categoria. Do universo analisado, por exemplo, nove publicações postadas não tiveram sua categoria aferida pelo usuário.

Para uma compreensão mais precisa deste trabalho, e por meio de uma análise mais qualitativa das publicações, cada item foi analisado e classificado segundo temáticas da área da Biblioteconomia e Ciência da Informação segundo a taxonomia proposta por Oddone e Gomes (2003). O Gráfico 3 apresenta a distribuição dessa classificação: 


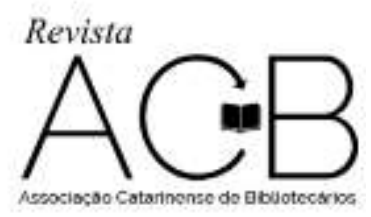

Revista ACB: Biblioteconomia em Santa Catarina, Florianópolis, v. 22, n. 3, p. 483-497, ago./nov., 2017.

GRÁFICO 3. Publicações classificadas de acordo com a taxonomia de Oddone e Gomes (2003)

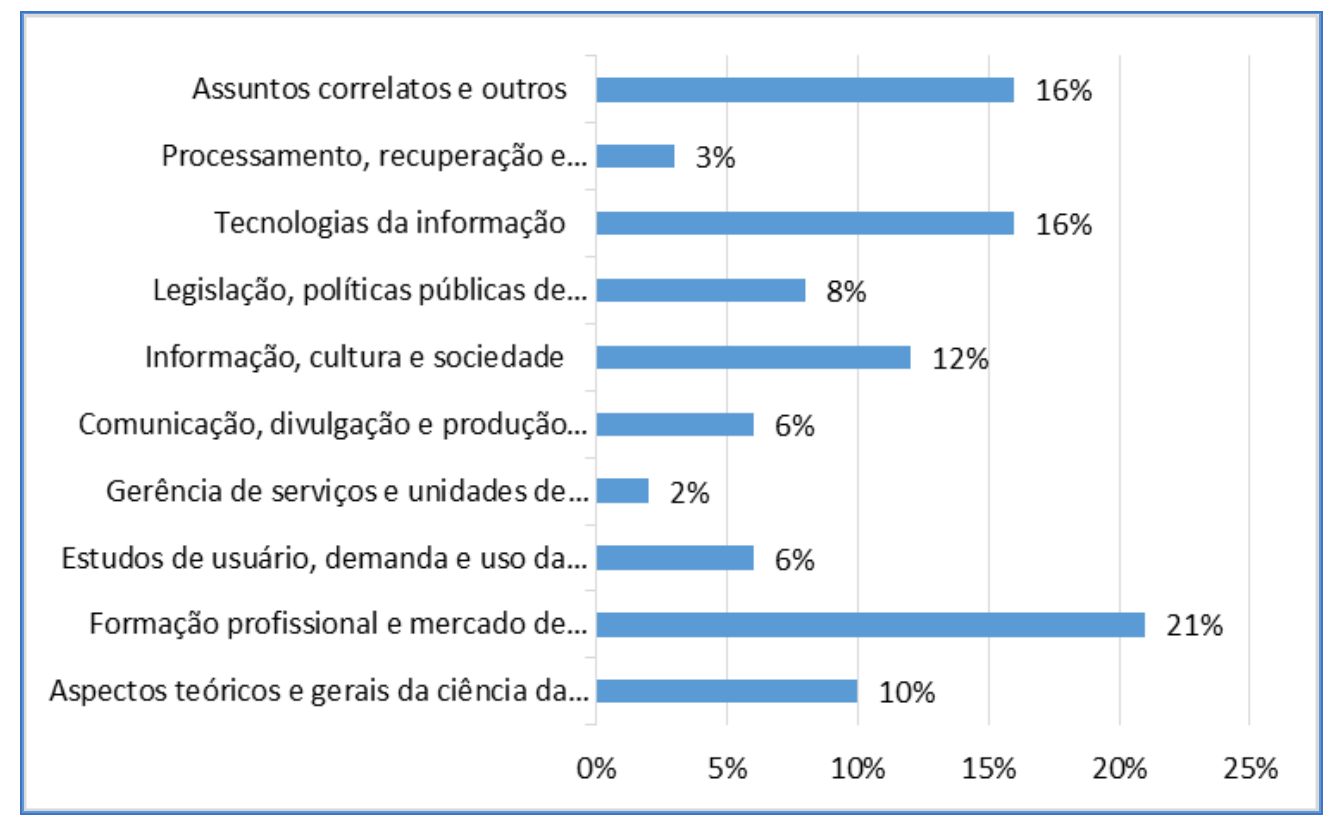

Fonte: Elaborado pelos autores, dados da pesquisa (2015).

A "Formação profissional e mercado de trabalho" do Bibliotecário teve o maior número de trabalhos e obteve $21 \%$. Isso demonstra que os usuários têm mais interesse nessa área. De acordo Oddone e Gomes (2003) esta categoria envolve estudos que tratam de questões curriculares, metodológicas, programáticas e de avaliação do ensino, tanto em nível de graduação como de pós-graduação, bem como análises sobre a formação e atuação profissional (perfil, habilidades, competências e atuação).

As categorias "Tecnologia da informação" e "Assuntos correlatos e outros" e apresentaram 16\% dos resultados cada uma. A primeira engloba trabalhos sobre o impacto e o uso das tecnologias de informação nos diferentes setores da sociedade, sobretudo nas unidades de informação, como implantação de sistemas, recursos para a automação, de redes eletrônicas de informação e sobre as bibliotecas virtuais, digitais e eletrônicas. Na estão textos sobre áreas limítrofes à Biblioteconomia e Ciência da Informação como informática, lingüística, comunicação social, leitura, literatura infanto-juvenil, dentre outras (ODDONE; GOMES, 2003).

Os trabalhos que se dedicam aos estudos da globalização, dos aspectos sociais e culturais da informação, bem como compreendem as unidades de informação enquanto espaços de comunicação e informação pertencem à categoria "Informação, cultura e sociedade" (ODDONE; GOMES, 2003) a qual apontou $12 \%$ do percentual. A categoria "Aspectos Gerais da Ciência da Informação", por sua vez, obteve $10 \%$. Nesta categoria estão trabalhos que abordam a fundamentação epistemológica da disciplina, a origem e a evolução da área, a interdisciplinaridade e a pesquisa científica, entre outros aspectos teóricos (ODDONE; GOMES, 2003).

A categoria "Legislação, políticas públicas de informação e de cultura", obteve $8 \%$. De acordo com Oddone e Gomes (2013) a categoria reúne textos sobre política bibliotecária, política de incentivo à leitura, política de informação e sobre política, gestão e planejamento de estruturas e sistemas de informação científica e tecnológica, bem como sobre economia da informação e política cultural. As demais categorias obtiveram menos de $10 \%$. 


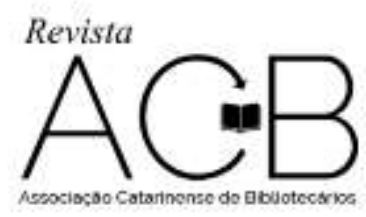

Revista ACB: Biblioteconomia em Santa Catarina, Florianópolis, v. 22, n. 3, p. 483-497, ago./nov., 2017.

\section{CONSIDERAÇÕES FINAIS}

O presente trabalho visou um estudo de mapeamento da produção de conteúdo sobre Biblioteconomia disseminado no Slideshare, com o intuito de mostrar sua representatividade enquanto área do conhecimento. Assim, as análises desenvolvidas nesta pesquisa permitiram conhecer, de alguma forma, os trabalhos publicados nessa rede, que não se restringem apenas a slides, mas também a artigos científicos, vídeos, imagens e entre outros.

A partir do levantamento realizado, na caracterização dos usuários, verificou-se que o gênero feminino prevalece sobre o masculino, embora alguns trabalhos tenham sido publicados em nomes de instituições - o que não permitiu categorização. Em se tratando dos perfis de formação/atuação dos usuários que publicam sobre Biblioteconomia no site, notamos que a maioria (65\%) é composta por profissionais bibliotecários e estudantes da área.

Em relação à interatividade do público com essa rede, percebeu-se que as publicações obtiveram um número elevado de visualizações, conferindo um bom desempenho ao indicador de visibilidade. No entanto, essa audiência não reflete as ações de informação expressas nos recursos de avaliações (curtidas), disseminação (compartilhamentos) e opiniões (comentários) que são gradativamente menores da primeira à última, indicando que os usuários são poucos participativos.

As categorias do SlideShare "Educação" e "Educação/Tecnologia" terem maior número de documentos sobre a Biblioteconomia e juntas representarem $49 \%$ do total analisado e a categoria "Formação Profissional e Mercado de Trabalho" da taxonomia Oddone e Gomes (2003) ter sido a principal, com $21 \%$ confirma o potencial do Slideshare para disseminação da informação e cooperação no processo de ensino-aprendizagem e de atuação profissional na área de Biblioteconomia.

Toda pesquisa científica está sujeita a entraves ou barreiras de realização ou mesmo situações que podem, em certa medida, comprometer seu bom desempenho. Uma limitação da pesquisa, que nos faz inclusive questionar o número reduzido de trabalhos analisados, está relacionada a aspectos do repositório Slideshare que podem ser aperfeiçoados, como por exemplo, seu mecanismo de busca que apresenta baixo índice de precisão. Isso acarreta excesso de conteúdos divergentes daquele tema que o usuário almeja em sua busca. Sugere-se outros estudos que busquem por eixos temáticos da área de Biblioteconomia e possam assim complementar essa análise inicial.

Por fim, salientamos o Slideshare é um dispositivo informacional que colabora para o processo de ensino e aprendizagem de diversas áreas do conhecimento e de setores variados. As apresentações depositadas não são de origem exclusiva da academia por professores e instrutores em contextos educacionais e de treinamento, mas também por outros profissionais como forma de dar visibilidade a sua prática profissional no mercado que atua. E nesse sentido, considera-se que essa rede social pode ser melhor explorada por acadêmicos e profissionais da área Biblioteconomia. 


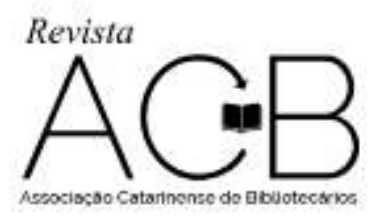

Revista ACB: Biblioteconomia em Santa Catarina, Florianópolis, v. 22, n. 3, p. 483-497, ago./nov., 2017.

\section{REFERÊNCIAS}

ALDRICH, H; ZIMMER, C. Entrepreneurship through social networks. In: SEXTON D. L.; SMILOR R. W. The art and science of entrepreneurship. Cambridge: Ballinger, 1986. p. 3-23.

ARAUJO, R. F.; TEIXEIRA, J. C. S.. Biblioteconomia conectada: uma análise da biblioblogosfera brasileira. Revista ACB: Biblioteconomia em Santa Catarina, Florianópolis, v. 18, p. 949-978, 2013.

ARAÚJO, R. F.. Atores e ações de informação em redes sociais na internet: pensando os regimes de informação em ambientes digitais. DataGramaZero, v.15, n.3, jun., 2014.

ARAÚJO, R. F. Estudos métricos da informação na web e o papel dos profissionais da informação. Bibliotecas universitárias: pesquisas, experiências e perspectivas, Belo Horizonte, v. 2, n. 1, p. 42-64, 2015.

BLATTMANN, U; SILVA, F. C. C. Colaboração e interação na Web 2.0 e Biblioteca 2.0. Revista ACB: Biblioteconomia em Santa Catarina, Florianópolis, v.12, n.2, p. 191-215, jul. / dez. 2007. Disponível em: <http://revista.acbsc.org.br/racb/article/view/530>. Acesso em: 09 jan. 2016.

CASTELLS, M. A galáxia da Internet: reflexões sobre a internet, os negócios e a sociedade. Rio de Janeiro: Jorge Zahar, 2003.

CORRÊA, E. C. D.; ZAMBAN, D.; OLIVEIRA, V. M. A.. Blogs sobre biblioteconomia e a ressignificação da profissão no brasil: uma análise do blog bibliotecários sem fronteiras. Revista ACB: Biblioteconomia em Santa Catarina, Florianópolis, v.18, n.1, p. 698-715, jan./jun., 2013

FIGUEIREDO, A. D. A geração 2.0 e os novos saberes. Revista do Centro de Investigação e Inovação em Educação, v. 2, n. 1, p. 79-91, 2012.

GUEDES, L. Como Aumentar O Alcance do Seu Conteúdo do LinkedIn. Luhguedes, mai., 2016. Disponível em: $<$ http://www.luhguedes.com/como-aumentar-o-alcance-do-seu-conteudo-do-linkedin/ $>$. Acesso em 02 ago. 2016.

HENN, G.; FLÁVIA, G. Biblioteconomia para concursos. 3. ed. Recife: Editora dos autores, 2014.

MARTELETO, R. M. Análise de redes sociais: aplicação nos estudos de transferência da informação. Ciência da Informação, Brasília, v. 30, n. 1, p. 71-81, jan./abr. 2001.

MUELLER, S. P. M. Métodos de pesquisa para a ciência da informação. Brasília: Thesaurus, 2007. $192 \mathrm{p}$.

ODDONE, N.; GOMES, M. Y. F. S. F. Os temas de pesquisa em Ciência da Informação e suas implicações político-epistemológicas. 2003. Disponível em: <http://www.cinformanteriores.ufba.br/v_anais/artigos/nancioddone.html>. Acesso em: 16 jun. 2016.

PIOVESAN, A.; TEMPORINI, E. R. Pesquisa exploratória: procedimento metodológico para o estudo de fatores humanos no campo da saúde pública. Rev Saúde Pública, v. 29, n. 4, p. 318-25, 1995. 
PRIMO, A. O aspecto relacional das interações na Web 2.0. E-Compós, Brasília, v. 9, p. 1-21, 2007. Disponível em: <http://www.ufrgs.br/limc/PDFs/web2.pdf>. Acesso em: 16. abr. 2016.

RECUERO, R. Redes Sociais na Internet. Porto Alegre: Sulinas, 2009.

RECUERO, R.; SOARES, P. Violência simbólica e redes sociais no facebook: o caso da fanpage "Diva Depressão". Galáxia. Revista do Programa de Pós-Graduação em Comunicação e Semiótica, n. 26, p. 239-254. 2013.

SLIDESHARE. Welcome to LinkedIn SlideShare! Disponível em: < www.pt.slideshare.net/about >.

THELWALL, M.; KOUSHA, K. SlideShare presentations, citations, users and trends: A professional site with academic and educational uses. Journal of the Association for Information Science and Technology, out., 2016. Disponível em: < http://wlv.openrepositoory.com/wlv/handle/2436/619242 >. Acesso em: 27 nov., 2016.

TOMAÉL M.; ALCARÁ A.; CHIARA I. D. Das redes sociais à inovação. Revista Ciência da Informação Brasília, v. 34, n. 2, p. 93-104, maio/ago. 2005. Disponível em: <http://www.scielo.br/pdf/ci/v34n2/28559.pdf>. Acesso em: 08 out. 2016.

WALTER, M. T. M. T.; BAPTISTA, S. G.. A força dos estereótipos na construção da imagem profissional dos bibliotecários. Inf. \& Soc.:Est., João Pessoa, v.17, n.3, p.27-38, set./dez. 2007

\title{
THE LIBRARIANSHIP IN SLIDESHARE: INTERACTIONS, CAPITAL AND THEMATIC ASPECTS
}

\begin{abstract}
It discusses the representativeness of Librarianship in the repository and social network site Slideshare through an exploratory study of cybermetric approach. The universe is composed of presentations resulting from manual searches for the term "Librarianship". The presentations are described according to the profile of their users / authors, levels of interactivity by social capital indicators - and thematic orientation of the SlideShare categorization and by a taxonomic classification. A total of 67 presentations were analyzed between 2007 and 2015. Regarding the profile of the users, the majority (65\%) were professionals librarians and librarianship students with predominance of the female gender and interaction destined to the cognitive social capital. With $42 \%$ the Education category prevails over the others as thematic orientation and in the application of the taxonomy, it is the "Training and labor market of the Librarian" (21\%). The results indicate the potential of Slideshare for the dissemination of information in the teaching and learning process and in the professional work in the Librarianship field.
\end{abstract}

Keywords: Social networks sites. Slideshare. Librarianship. Dissemination of information. 


\section{RONALDO FERREIRA DE ARAUJO}

Doutor em Ciência da Informação pelo Programa de Pós-Graduação em Ciência da Informação da Escola de Ciência da Informação da Universidade Federal de Minas Gerais (UFMG). Mestre em Ciência da Informação pelo Programa de Pós-Graduação em Ciência da Informação da Escola de Ciência da Informação da Universidade Federal de Minas Gerais (UFMG). Graduado em Ciência da Informação pela Pontifícia Universidade Católica de Minas Gerais (PUC Minas). E-mail: ronaldfa@gmail.com

\section{JONISMAR KENDYS DA SILVA LEÃO}

Graduando em Biblioteconomia pela Universidade Federal de Alagoas (UFAL). E-mail: jonnis@hotmail.com

\section{MARIA ROSELENE CARDOSO DE BARROS}

Graduanda em Biblioteconomia pela Universidade Federal de Alagoas (UFAL). E-mail: roselene.cb@hotmail.com

RECEBIDO EM: 23-06-2017

ACEITO EM: 23-09-2017 